\title{
A Review on applications of Silver diamine fluoride in dentistry
}

\author{
${\text { Meena Jain }{ }^{1, *} \text {, Vishal Jain², Nidhi Agarwal }}^{3}$ \\ ${ }^{1}$ Reader, Dept. of Public Health Dentistry, Manav Rachna Dental College, Faridabad, Haryana, ${ }^{2}$ Postgraduate Student, ${ }^{3}$ Professor \\ \& HOD, Dept. of Pedodontics and Preventive Dentistry, Institute of Dental Studies and Technologies, Modinagar, Uttar Pradesh, \\ India
}

*Corresponding Author:

Email: drmeenabansal@gmail.com

\begin{abstract}
Various studies in literature worldwide report high prevalence of Early Childhood caries (ECC). Traditional restorative methods for ECC are not always affordable or possible, as it require patient cooperation for desirable outcome. Silver diamine fluoride (SDF) was first promoted in Japan in late 1960's. It is painless and simple to use for young children or patients with special needs. When SDF is applied on carious lesions, the fluoride enhances remineralization and the silver ions act as an antibacterial agent and inhibit the growth of cariogenic biofilms. SDF also preserves the dentin collagen from further degradation. SDF at $38 \%$ has been used mostly in various countries.
\end{abstract}

Keywords: Dental caries, Fluoride, Public health tool.

\section{Introduction}

Early childhood caries is an infectious, and transmissible disease of teeth affecting young children caused by various factors and is related with susceptible, uninsured, and financially weak populations. ${ }^{1}$ It is also the most prevalent condition included in the 2015 Global Burden of Disease Study, ranking 12th for deciduous teeth affecting 560 million children. ${ }^{2}$ Untreated decay in very young children can lead to increased risk of caries in other deciduous and permanent teeth, missed school hours, pain, and infections; costly emergency treatments; due to widespread decay and the associated requirement for general anesthesia; and limited growth as well as development. $^{3} \quad$ Therefore, untreated caries and underutilization of dental services are two most prominent public health problems for children in developing and undeveloped nations. ${ }^{1}$

It is essential to search an efficient, affordable method of treating dental caries in preschool children who are at high risk of caries and with restricted access to dental care to decrease the burden of untreated caries. ${ }^{4}$ The conventional management for a decayed tooth involves removal of infected and demineralized tooth structure and subsequent replacement with a filling material. ${ }^{5}$ Additionally, management of dental caries can be difficult and may require highly developed skill of the dentist as well as extensive instrumentation and restoration cost. Also, good cooperation from patient is mandatory. This is especially difficult in case of very young children due to their limited adaptive capacity. Hence, managing a carious tooth in such children can be a riddle for the provider. In such cases, arresting caries treatment has been proposed to manage untreated dental caries. ${ }^{6}$ In recent times, SDF has been popularized for its capability to stop the caries progression and concurrently arrest the formation of new carious lesions. ${ }^{7}$ Also, SDF can be used in children who are too young to have their carious teeth restored by traditional methods. In addition, SDF application can be an affordable way of managing dental decay in many children from low income families or living in areas where there is limited access to dental service provider.

\section{History}

Japanese used silver as tooth cosmetics to prevent dental caries since 1000 years. ${ }^{8}$ In 1891, silver amalgam and nitric acid was used on carious teeth and had caries arresting properties. ${ }^{9}$ Silver nitrate was directly applied to carious cavities with analogous outcomes, and it was termed as Howe's solution, which was used for caries inhibition. ${ }^{10}$ In Western Australia, $40 \%$ silver fluoride $(\mathrm{AgF})$ was applied as the treatment for deep dental caries in primary teeth at school dental care services. ${ }^{11}$

Till late 1960s and 1970s, SDF was not much exposed to other parts of the world other than Japan. Since 1960's, it was established as a therapeutic agent by the Central Pharmaceutical Council of the Ministry of Health and Welfare in Japan for dental treatment. ${ }^{11}$ For past few decades, SDF has also been in used in Australia $^{12}$ and China ${ }^{13}$ to prevent dental decay. SDF has been used in many community dental health programs in various concentrations has been used in Argentina, Brazil and Spain; and additionally community health programmes were designed for subSaharan Africa and for other countries of Africa. ${ }^{14}$ Although an article in an American journal published in 1995 reported that there were health care providers in Southern California who applied SDF to seize caries progress in young children with early childhood caries. ${ }^{15}$ However, SDF was not commonly available in some countries of Europe and the USA. In 2014, SDF was approved by the US Food and Drug Administration for management of tooth hypersensitivity. ${ }^{7}$ 
Though its extensive use started in China in start of $21^{\text {st }}$ century as a caries arresting agent in school going children. ${ }^{16,17}$ From 2005 to 2009 in Australia, a series of in vitro studies were conducted and proved effect of SDF on Streptococcus mutans and dental bio-film as a caries arresting and antimicrobial agent respectively. ${ }^{18-}$ ${ }^{21}$ In Yee et al. ${ }^{22}$ in Nepal and 2009 Braga et al. ${ }^{23}$ in US used SDF as caries arresting agent. In 2013, SDF was used to prevent root caries in elderly. ${ }^{24}$ Studies were conducted in India providing literature of successful use of SDF as a caries arresting agent. ${ }^{25,26}$ A study in 2018 found that SDF was successful in arresting active caries in primary teeth of young children in USA and was also well received by their parents. ${ }^{4}$ Still, many studies are being conducted in various countries of the world to establish SDF as an aid for the dental public health community professionals to address dental caries in atrisk populations.

\section{SDF versus Silver Fluoride}

Silver fluoride $\left(\mathrm{SnF}_{2}\right)$ is a neutral colored solution having silver ions and fluoride ions. It is highly alkaline $(\mathrm{pH}=11)$, which requires a two-stage application procedure using $\mathrm{SnF}_{2}$ as a reducing agent. $\mathrm{SDF}$ is proved to be more non reactive and can be maintained at a constant concentration. SDF is comparatively less alkaline $(\mathrm{pH}=8-9)$ than $\mathrm{AgF}$ and does not need a reducing agent.

Although $\mathrm{SnF}_{2}$ is much more soluble in water than the other silver halides, it forms colourless cubic crystals. SDF is formed of ammonia and $\mathrm{SnF}_{2}$. The ammonia ions coalesce with the silver ions to generate a complex ion called the diamine-silver ion, $\left[\mathrm{Ag}\left(\mathrm{NH}_{3}\right)_{2}\right]+$. Construction of these diamine- silver ions is a reversible reaction and is very stable.

While AgF is not easily accessible, though SDF is widely available as $38 \%$ solution in a commercial preparation and is available in Japan as Saforide (Toyo Seiyaku Kasei Ltd, Osaka, Japan). Saforide has 380 mg water-soluble SDF in $1 \mathrm{ml}$ colourless aqueous solution, or about $44,800 \mathrm{ppm}$ of fluoride ions. SDF is commercially available in South America as Fluoroplat (LaboratoriosNaf, Buenos Aires, Argentina) and Safluoride di Walter in $10 \%$ solution (Polidental, Rio de Janeiro, Brazil). A $38 \%$ SDF solution is also available in Australia (Creighton Pharmaceutical, Sydney, Australia). In India, it is available in $38 \%$ concentration by brand name FAgamin.

\section{Mechanism of Action}

There could be following possible mechanisms of action of SDF against caries:

1. The first mechanism may be the occlusion of dentinal tubules with silver. According to Shimizu, ${ }^{27}$ when SDF is applied on dentine, its dye permeability reduced and electric resistance enhanced. He also reported that silver and its compounds from SDF application blocked the diffusion of acid and invasion of microorganisms into the dentinal tubules. It also inhibited the further growth of microorganisms by oligodynamic action of silver. ${ }^{28}$ Additionally, obturation of the dentinal tubules decreased the surface area of dentin, which may be attacked by caries. It has also been seen that the use of $38 \%$ SDF repressed demineralization and preserved collagen from degradation in demineralized dentin. ${ }^{29}$

2. The other mechanisms could be the cariostatic action of products produced by reaction between SDF and minerals of the tooth. The fluoride present in amplified the resistance of the dentin to action of acid resulting in reduced penetration of acid into inner dentin. ${ }^{30}$ When SDF is applied to dentin under in vivo conditions, its fluoride ions penetrated to a depth of $50-100 \mu{ }^{31}$ It has been proved that $\mathrm{SDF}\left(\mathrm{Ag}\left(\mathrm{NH}_{3}\right)_{2} \mathrm{~F}\right)$ reacts with hydroxyapatite (HA) of tooth to release calcium fluoride $\left(\mathrm{CaF}_{2}\right)$ and silver phosphate $\left(\mathrm{Ag}_{3} \mathrm{PO}_{4}\right)$, resulting in hardening of affected dentine.

A basic chemical reaction is shown below:

$\mathrm{Ca}_{10}\left(\mathrm{PO}_{4}\right)_{6}(\mathrm{OH})_{2}+\mathrm{Ag}\left(\mathrm{NH}_{3}\right)_{2} \rightarrow \mathrm{CaF}_{2}+\mathrm{Ag}_{3} \mathrm{PO}_{4}+$ $\mathrm{NH}_{4} \mathrm{OH}$

$\mathrm{CaF}_{2} \rightarrow \mathrm{Ca}^{++}+2 \mathrm{~F}^{-}$

$\mathrm{Ca}_{10}\left(\mathrm{PO}_{4}\right)_{6}(\mathrm{OH})_{2}+2 \mathrm{~F}^{-} \rightarrow \mathrm{Ca}_{10}\left(\mathrm{PO}_{4}\right)_{6} \mathrm{~F}_{2}+2 \mathrm{OH}^{-}$

The $\mathrm{Ag}_{3} \mathrm{PO}_{4}$ that is formed on the tooth is insoluble to acid attacks. The $\mathrm{CaF}_{2}$ formed as a reaction product becomes a pool of fluoride ions for the formation of fluorapatite $\left(\mathrm{Ca}_{10}\left(\mathrm{PO}_{4}\right)_{6} \mathrm{~F}_{2}\right){ }^{32}$ It is also proved that fluoride ions enhances calcification of tooth, and restores lattice imperfection, ${ }^{33}$ and improves the crystallinity of HA. ${ }^{34}$

3. The anti-enzymatic actions of the reaction products between $\mathrm{Ag}\left(\mathrm{NH}_{3}\right)_{2} \mathrm{~F}$ and organic component of the tooth can be the next mechanism of action for caries arrest. Its antibacterial properties arise from inhibition of the enzyme activities and dextraninduced agglutination of cariogenic strains of Streptococcus mutans. ${ }^{35}$ Resistance of dentin to trypsin increased when SDF is applied on tooth surface. ${ }^{36}$ Also, a study reported that resistance to collagenase and trypsin for dentin protein increased after treating the tooth with SDF. ${ }^{37}$

\section{Clinical Applications}

1. For management of patients with high caries prevalence like with xerostomia.

2. Management of difficult young children with behavioral problems.

3. To arrest caries in anterior primary teeth of young children- Earlier rampant caries was treated with removal of carious dentin and temporary restoration with zinc oxide eugenol. SDF can provide a better substitute for the such patients of irregular caries pattern. 
4. SDF is effective in arresting dentin caries in a Community-based Caries Control Program- SDF can be used to tackle the caries problem in community dental health programs especially in developing and low income countries. The main advantages could be ${ }^{14}$ :

a. Control of pain and infection with affordable cost.

b. Simplicity of treatment- so non-professionals can also apply SDF.

c. Minimal support required so is feasible without piped water and electricity.

d. Non-invasive procedure, thus the risk of spreading infection is very low.

5. To prevent pit and fissure caries- SDF can be effective for the prevention of pits and fissures caries of the first molar. ${ }^{38}$ A study mentioned that fissure caries were less in SDF applied teeth when compared with $\mathrm{SnF}_{2} 8 \%$ or $\mathrm{Ag}(\mathrm{NO})_{3} .{ }^{39}$ However, because of grayish-black and black stain at the pit and fissure by SDF may be mistaken for incipient caries, so the application should be mentioned appropriately in records.

6. To prevent further caries

7. Annual application of SDF is effective in arresting the root caries.

8. SDF has an ability to occlude the dentinal tubule so is used for dentinal hypersensitivity and 4 times repeated application was suitable for its treatment. $^{40}$

9. To disinfect root canals- SDF can be effectively used as an endodontic irrigant. ${ }^{41}$

10. For the patients who have behavioral or medical management issues.

\section{Contraindications ${ }^{42}$}

1. Allergy to silver

2. Pregnancy

3. Breastfeeding

4. Ulcerative gingivitis

5. Stomatitis

\section{Safety ${ }^{42}$}

Average LD50 by oral administration is 520 $\mathrm{mg} / \mathrm{kg}$, and by subcutaneous administration is 380 $\mathrm{mg} / \mathrm{kg}$. One drop $(25 \mu \mathrm{L})$ is sufficient to treat 5 teeth, and has $9.5 \mathrm{mg}$ SDF. Suppose the child patient can be of $10 \mathrm{~kg}$, the dose would be $0.95 \mathrm{mg} / \mathrm{kg}$ child. Hence, the relative safety margin of utilizing a full drop on a $10 \mathrm{~kg}$ child is: $380 \mathrm{mg} / \mathrm{kg} \mathrm{LD} 50 / 0.95 \mathrm{mg} / \mathrm{kg}$ dose = 400-fold safety margin.

\section{Procedure to apply SDF}

1. Cover the counter with plastic and drape the patient with plastic bib.

2. Standard personal protective equipment to be worn by both patient and Provider.
3. Dispense one drop $(25 \mathrm{uL} / 10 \mathrm{~kg}$ per treatment visit) 42 of SDF in dappen dish.

4. Isolate and dry the affected teeth / tooth.

5. Apply petroleum jelly on gingiva.

6. Apply SDF on teeth with a smallest microsponge.

7. Wait for 1 minute ${ }^{42}$ after application and remove the excess with cotton gauge.

8. Rinse with water.

9. Repeat the procedure every 6 months. ${ }^{42}$

\section{Adverse effects}

When SDF was applied to several teeth to arrest or prevent dental caries in various interventional studies, the only side effect reported was for 3 subjects who followed for up to 3 years reported "a small, mildly painful white lesion in the mucosa, which disappeared after 2 days without treatment."16,17,22,24 No adverse pulpal response was observed.

\section{Non-medical side effects}

1. SDF darkens carious lesions.

2. Patients may experience a transient metallic or bitter taste.

3. Little amount of SDF can result in "temporary tattoo" on skin but does no harm. Stain on the skin diminish with the natural skin exfoliation, in 2-14 days.

4. SDF stains clinic surfaces and clothes. Spills to be cleaned up immediately with copious water, ethanol, or bleach.

\section{Effects on bonding of dental materials to tooth}

1. SDF had no effect on bonding of composite to noncarious dentin using either self-etch or light cure etch systems. $^{43}$

2. In a study, rinsing with water after SDF application prevented a $50 \%$ decrease in bond strength for GIC. ${ }^{44}$ In another study, increased dentin bond strength to GIC was observed. ${ }^{45}$

3. SDF decreased dentin bonding strength of resinbased crown cement by $\sim 1 / 3{ }^{46}$ As a result, rinsing will be adequate for direct restorations, while removal of the SDF treated superficial dentin will be advisable for cementing crowns.

\section{Conclusion}

Application of SDF biannually is better than all other minimally invasive treatment choices. However, it is unclear what will happen if treatment is stopped after 2-3 years and further research is required. SDF is more effective as a primary preventive material than other restorative materials which are available, except dental sealants which are $>10$ times more costly and needs professional follow up.

The use of SDF as a preventive or therapeutic modality can prevent or delay dental treatment for all age groups. It can easily replace fluoride varnish for the caries arrest in subjects that have active caries. It is a 
powerful public health tool in the fight against dental caries especially in low income countries.

\section{Conflict of Interest: Nil}

\section{References}

1. Dye BA, Thornton-Evans G, Li X, Iafolla TJ. Dental caries and sealant prevalence in children and adolescents in the United States, 2011-2012. NCHS Data Brief. 2015;3(191):1-8.

2. GBD 2015 Disease and Injury Incidence and Prevalence Collaborators (2016). Global, regional, and national incidence, prevalence, and years lived with disability for 310 diseases and injuries, 1990-2015: a systematic analysis for the Global Burden of Disease Study 2015. Lancet 388(10053):1545-602.

3. da Silva BastosVde A, Freitas-Fernandes LB, Fidalgo TK, Martins C, Mattos CT, de Souza IP, Maia LC. Mother-to child transmission of Streptococcus mutans: a systematic review and meta-analysis. J Dent 2015;43(2):181-91.

4. Clemens J, Gold J, Chaffin J. Effect and acceptance of silver diamine fluoride treatment on dental caries in primary teeth. J Pub Health Dent 2018;78(1):63-8.

5. Roberson TM, Heymann HO, Swift EJ. Sturdevant's Art and Science of Operative Dentistry. Mosby: St. Louis; 2002.

6. $\quad$ Bedi R, Sardo-Infirri J Oral health care in disadvantaged communities, London: FDI world press 1999.

7. Rosenblatt A, Stamford TCM, Niederman R. Silver Diamine Fluoride: A Caries "Silver Fluoride Bullet". $J$ Dent Res 2009 88:116-25.

8. Yamaga R, Nishino M, Yoshida S et al. Diamine silver fluoride and its clinical application. J Osaka Univ Dent Sch 1972 12:1-20.

9. Stebbins EA. What value has argentinitras as a therapeutic agent in dentistry? Int Dent J 1891 12:661670.

10. Howe PR. A method of sterilizing and at the same time impregnating with a metal affected dentinal tissue. Dent Cosmos 1917;59:891-904.

11. Yamaga R, Yokomizo I. Arrestment of caries of deciduous teeth with diamine silver fluoride. Dent Outlook 1969;33:1007-13.

12. Gotjamanos T. Pulp response in primary teeth with deep residual caries treated with silver fluoride and glass ionomer cement ('atraumatic' technique). Aust Dent $J$ 1996;41:328-34.

13. Li YJ. Effect of a silver ammonia fluoride solution on the prevention and inhibition of caries. Zhonghua Kou QiangKeZaZhi 1984;19:97-100 [in Chinese].

14. Bedi R, Infirri JS. Oral Health Care in Disadvantaged Communities. London: FDI World Dental Press, 1999.

15. Duperon DF. Early childhood caries: a continuing dilemma. J Calif Dent Assoc 1995;23:15-25.

16. Chu $\mathrm{CH}$, Lo EC, Lin HC. Effectiveness of silver diamine fluoride and sodium fluoride varnish in arresting dentin caries in Chinese preschool children. J Dent Res 2002, 81:767-70.

17. Llodra JC, Rodriguez A, Ferrer B et al. Efficacy of silver diamine fluoride for caries reduction in primary teeth and first permanent molars of schoolchildren: 36-month clinical trial. J Dent Res 2005,84:721-4.

18. Knight GM, McIntyre JM, Craig GG et al. An in vitro model to measure the effect of a silver fluoride and potassium iodide treatment on the permeability of demineralized dentine to Streptococcus mutans. Aust Dent J 2005 50:242-5.

19. Knight GM, Mclntyre JM, Craig GG et al. Ion uptake into demineralized dentine from glass-ionomer cement following pretreatment with silver fluoride and potassium iodide. Aust Dent J 2006;51:237-41.

20. Knight GM, Mclntyre JM, Craig GG et al. Differences between normal and demineralized dentine pretreated with silver fluoride and potassium iodide after an in vitro challenge by Streptococcus mutans. Aust Dent $J$ 2007;52:16-21.

21. Knight GM, Mclntyre JM, Craig GG et al. Inability to form a biofiim of Streptococcus mutans on silver fluoride- and potassium iodide treated demineralized dentin. Quintessence Int 2009;40:155-61.

22. Yee R, Holmgren C, Mulder J et al. Efficacy of silver diamine fluoride for Arresting Caries Treatment. J Dent Res 2009;88:644-7.

23. Braga MM, Mendes FM, De Benedetto MS et al. Effect of silverdiammine fluoride on incipient caries lesions in erupting permanent first molars: a pilot study. J Dent Child 2009;76:28-33.

24. Zhang W, McGrath C, Lo EC, Li JY. Silver diamine fluoride and education to prevent and arrest root caries among community-dwelling elders. Caries Res 2013;47(4):284-90.

25. Shah S, Bhaskar V, Venkataraghavan K, Choudhary P, Ganesh M, Trivedi K. Efficacy of silver diamine fluoride as an antibacterial as well as antiplaque agent compared to fluoride varnish and acidulated phosphate fluoride gel: An in vivo study. Indian Journal of Dent Res 2013;24(5):575.

26. Gugnani N, Gugnani S. Remineralisation and arresting caries in children with topical fluorides. Evidence-based Dent 2017;18(2):41.

27. Shimizu A. Effect of diammine silver fluoride on recurrent caries. Jap J Conserv Dent 1974;17:183-201. (in Japanese, summary in English)

28. Yamaga R. Mechanisms of action of diammine silver fluoride and its use. Nippon Dent. Rev 1970;328:180-7. (In Japanese)

29. Mei ML, Ito L, Cao Y, Li QL, Chu CH, Lo EC. The inhibitory effects of silver diamine fluorides on cysteine cathepsins. J Dent 2013. doi:pii: S0300-5712(13)003187 .

30. Selvig K. A. Ultrastructural changes in human dentine exposed to a weak acid. Archs oral Biol 1968;13:719-34.

31. Shimooka S. On the penetration of silver nitrate and ammoniacal silver fluoride into microstructure of the sound dentin. J Nippon Dent Coll 1972;59:534-66.

32. Suzuki T, Nishida M, Sobue $\mathrm{S}$ et al. Effects of diamine silver fluoride on tooth enamel. J Osaka Univ Dent Sch 1974;14:61-72.

33. Kani T. X-ray diffraction studies on effect of fluoride on restoration of lattice imperfections of apatite crystals. $J$. Osaka Univ. Dent. Soc 1970;15:42-56.

34. Tamaki S. Effects of fluoride on crystallinity of synthetic and biological apatite. J Osaka Univ Dent. Soc 1967;12:95-110.

35. Suzuki T, Sobue S, Suginaka H. Mechanism of antiplaque action of diamine silver fluoride. J Osaka Univ Dent Sch 1976;16:87-95.

36. Sunada I, Kuriyama S, Komamura $\mathrm{T}$ et al. Resistance to acid and enzyme of dentin treated by metal ion ionophoresis. Jap. J Conserv Dent 1962;5:6-10.

37. Yanagida I, Nishino M, Hano T et al. Effects of diammine silver fluoride on organic components of dentin of deciduous teeth. Jap J Pedo 1971;9:39-46. 
38. Sato R, Sailo Y. Clinical Application of Silver Ammonia Fluoride (Saforide) to Children. Nippon Dent Review 1970;332,66-7.

39. Nishino M, Massler M. Immunization of Cariessusceptible Pits and Fissures with a Diammine Silver Fluoride Solution, Jap J Pedod 1972;10:6-11.

40. Kimura K, Iso Y, Ohno. M et al. Clinical Test of Diammine Silver Fluoride (Saforide) Applied to Hypersensitive Dentin. Shikagakuho 1971;71:708-13.

41. Mathew VB, Madhusudhana K, Sivakumar N, Venugopal T, Reddy RK. Anti-microbial efficiency of silver diamine fluoride as an endodontic medicament - An ex vivo study. Contemp Clin Dent 2012;3(3):262-4.

42. Horst JA, Ellenikiotis H, Milgrom PM, UCSF Silver Caries Arrest Committee. UCSF protocol for caries arrest using silver diamine fluoride: rationale, indications, and consent. J California Dent Asso 2016;44(1):16.

43. Quock RL, Barros JA, Yang SW, Patel SA. Effect of Silver Diamine Fluoride on Microtensile Bond Strength to Dentin. Oper Dent 2012;37(6):610-6. Doi:10.2341/11344-L

44. Knight GM, McIntyre JM, Mulyani. The effect of silver fluoride and potassium iodide on the bond strength of auto cure glass ionomer cement to dentine. Aus Dent $J$ 2006;51(1):42-5.

45. Yamaga M, Koide T, Hieda T. Adhesiveness of glass ionomer cement containing tannin-fluoride preparation (HY agent) to dentin--an evaluation of adding various ratios of $\mathrm{HY}$ agent and combination with application diammine silver fluoride. Dent Mater J 1993;12(1):3644.

46. Soeno K, Taira Y, Matsumura H, Atsuta M. Effect of desensitizers on bond strength of adhesive luting agents to dentin. J Oral Rehabil 2001;28(12):1122-8. 